\title{
Correction to: Olivier's theorem: ideal convergence, algebrability and Borel classification
}

\section{Artur Bartoszewicz ${ }^{1}$ (D) Szymon Głąb $^{2}$ (D) Agnieszka Widz ${ }^{2}$}

Published online: 17 November 2021

(c) The Author(s) under exclusive licence to The Royal Academy of Sciences, Madrid 2021

\section{Correction to: RACSAM (2021) 115:200 https://doi.org/10.1007/s13398-021-01143-y}

Unfortunately, the affiliation of the author Szymon Głab is cited wrongly affiliated.

The correct affiliation should be Institute of Mathematics, Łódź University of Technology, ul. Wólczanska 215, 93-005 Lodz, Poland.

Publisher's Note Springer Nature remains neutral with regard to jurisdictional claims in published maps and institutional affiliations.

The original article can be found online at https://doi.org/10.1007/s13398-021-01143-y.

Szymon Głąb

szymon.glab@p.lodz.pl

Artur Bartoszewicz

artur.bartoszewicz@wmii.uni.lodz.pl

Agnieszka Widz

agnieszkawidzenfp@gmail.com

1 Faculty of Mathematics and Computer Science,

Łód[PleaseinsertlPrerenderUnicode $\left\{\AA^{\circ}\right\}$ intopreamble] University, ul. Stefana Banacha 22,

90-238 Łód[Pleaseinsert\PrerenderUnicode $\left\{\AA^{\circ}\right\}$ intopreamble], Poland

2 Institute of Mathematics, Łód[Pleaseinsert\PrerenderUnicode $\left\{\AA^{\circ}\right\}$ intopreamble] University of Technology, ul. Wólcza[Pleaseinsert $\$ PrerenderUnicode $\{\AA ̊,$,$\} intopreamble]ska 215, 93-005 Lodz, Poland$ 